\title{
THE WHITE HOUSE
}

WASHINGTON

May 22, 1998

PRESIDENTIAL DECISION DIRECTIVE/NSC-63

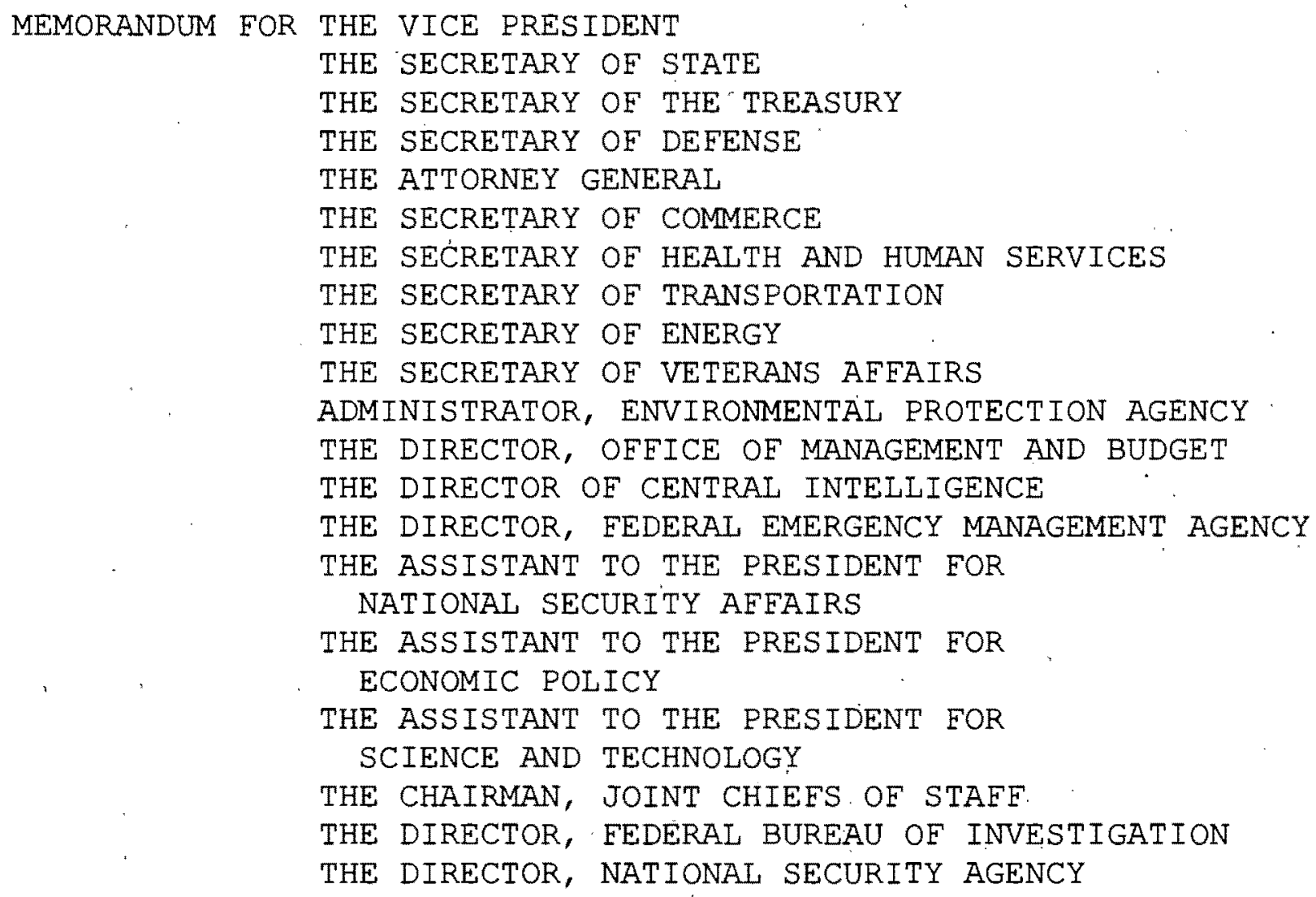

SUBJECT: Critical Infrastructure Protection

I. A Growing Potential Vulnerability

The United States possesses both the world's strongest military and its largest national economy. Those two aspects of our power are mutually reinforcing and dependent. They are also increasingly reliant upon certain critical infrastructures and upon cyber-based information systems.

Critical infrastructures are those physical and cyber-based systems essential to the minimum operations of the economy and government. They include, but are not limited to, telecommunications, energy, banking and finance, transportation, 
water systems and emergency services, both governmental and private. Many of the nation's critical infrastructures have historically been physically and logically, separate systems that had little interdependence. As a result of advances in information technology and the necessity of improved efficiency, however, these infrastructures have become increasingly automated and interlinked. These same advances have created new vulnerabilities to equipment failures, human error, weather and other natural causes, and physical and cyber attacks: Addressing these vulnerabilities will necessarily require flexible, evolutionary approaches that span both the public and private sectors, and protect both domestic and international security.

Because of our military strength, future enemies, whether nations, groups or individuals, may seek to harm us in nontraditional ways including attacks within the United States. Because our economy is increasingly reliant upon interdependent and cyber-supported infrastructures, non-traditional attacks on our infrastructure and information systems may be capable of significantly harming both our military power and our economy.

\section{President's Intent}

It has long been the policy of the United States to assure the continuity and viability of critical infrastructures. I intend that the United States will take all necessary measures to swiftly eliminate any significant vulnerability to both physical and cyber attacks on our critical infrastructures, including. especially our cyber systems.

\section{A National Goal}

No later than the year 2000, the United States shall have achieved an initial operating capability and no later than five years from today the United.States shall have achieved and shall maintain the ability to protect our nation's critical infrastructures from intentional acts.that would significantly diminish the abilities of:

- the Federal Government to perform essential national security missions and to ensure the general public health and safety;

- state and local governments to maintain order and to deliver minimum essential public services; 
- the private sector to ensure the orderly functioning of the economy and the delivery of essential telecommunications, energy, financial and transportation services.

Any interruptions or manipulations of these critical functions must be brief, infrequent, manageable, geographically isolated and minimally detrimental to the welfare of the United states.

IV. A Public-Private Partnership to Reduce Vulnerability

Since the targets of attacks on our critical infrastructure would likely include both facilities in the economy and those in the government, the elimination of our potential vulnerability requires a closely coordinated effort of both the government and the private sector. To succeed, this partnership must be genuine, mutual and cooperative. In seeking to meet our national goal to eliminate the vulnerabilities of our critical infrastructure, therefore, we should, to the extent feasible, seek to avoid outcomes that increase government regulation or expand unfunded government mandates to the private sector.

For each of the major sectors of our economy that are vulnerable to infrastructure attack, the Federal Government will appoint from a designated Lead Agency a senior officer of that agency as the sector Liaison official to work with the private sector. sector Liaison officials, after discussions and coordination with private sector entities of their infrastructure sector, will identify a private sector counterpart (Sector. Coordinator) to represent their sector.

Together these two individuals and the departments and corporations they represent shall contribute to a sectoral National Infrastructure Assurance Plan by:

- assessing the vulnerabilities of the sector to cyber or physical attacks;

- recommending a plan to eliminate significant vulnerabilities;

- proposing a system for identifying and preventing attempted major attacks;

- developing a plan for alerting, containing and rebuffing an attack in progress and then, in coordination with EEMA as appropriate, rapidly reconstituting minimum essential capabilities in the aftermath of an attack. 
During the preparation of the sectoral plans, the National Coordinator (see section VI), in conjunction with the Lead Agency Sector Liaison officials and a represientative from the National Economic Council, shall ensure their overail coordination and the integration of the various seictoral plans, with a particular focus on interdependencies.

V. Guidelines

In addressing this potential vilnerability and the means of eliminating it, I want those involved to be mindful of the following general principles and concerns.

- We shall' consult with, and seek input from, the Congress on approaches and programs to meet the objectives set forth in this directive.

- The protection of our critical infrastructures is necessarily a shared responsibility and partnership between owners, operators and the government. Furthermore, the Federal Government shall encourage international cooperation to help manage this increasingly global problem.

- Frequent assessments shall be made of our critical infrastructures' existing reliability, vulnerability and threat environment because, as technology and the nature of the threats to our critical infrastructures will continue to change rapidly, so must our protective measures and responses be robustly adaptive.

- The incentives that the market provides are the first choice for addressing the problem of critical infrastructure protection; regulation will be used only in the face of a material failure of the market to protect the health, safety or well-being of the American people. In such cases, agencies shall identify and assess available alternatives to direct regulation, including providing economic incentives to encourage the desired behavior, or providing information upon which choices can be made by the private sector. These incentives, along with other actions, shall be designed to help harness the latest technologies, bring about global solutions to international problems, and enable private sector owners and operators to achieve and maintain the maximum feasible security. 
- The full authorities, capabilities and resources of the government, including'law.enforcement, regulation, foreign intelligence and defense preparedness shall: be available, as appropriate, to ensure that critical infrastructure protection is achieved and maintained.

- Care must be taken to respect privacy rights. Consumers and operators must have confidence' that information will be handled accurately, confidentially and reliably.

- The Federal Government shall, through its research, development and procurement, encourage the introduction of increasingly capable methods of infrastructure protection.

- The Federal Government shall serve as a model to the private sector on how infrastructure assurance is best achieved and shall, to the extent feasible, distribute the results of its endeavors.

- We must focus on preventative measures as well as threat and crisis management. To that end, private sector owners and operators should be encouraged to provide maximum feasible security for the infrastructures they control and to provide the government necessary information to assist them in that task. In order to engage the private sector fully, it is preferred that participation by owners and operators in a national infrastructure protection system be voluntary.

- Close cooperation and coordination with state and local governments and first responders is essential for a robust and flexible infrastructure protection program. All critical infrastructure protection plans and action shall take into consideration the needs, activities and responsibilities of state and local governments and first responders.

VI. Structure and Organization

The Federal Government will be organized for the purposes of this endeavor around four components (elaborated in Annex A).

1. Lead Agencies for Sector Liaison: For each infrastructure sector that could be a target for significant cyber or physical attacks, there will be a single:U.S. Government department which will serve as the lead agency for liaison. Each Lead Agency will designate one individual of Assistant 
Secretary rank or higher to be the sector Liaison official for that area and to cooperate with the private sector representatives (Sector Coordinators) in addressing problems related to critical infrastructure protection and, in particular, in recommending components of the National Infrastructure Assurance Plan. Together, the Lead Agency and the private sector counterparts will develop and implement a Vulnerability Awareness and Education Program. for their sector.

2. Lead Agencies for Special Eunctions: There are, in addition, certain functions related to critical infrastructure protection that must be chiefly performed by the Federal Government (national defense, foreign affairs, intelligence, law enforcement). For each of those special functions, there shall be a Lead Agency which will be responsible for coordinating all of the activities of the United States Government in that area. Each lead agency will appoint a senior officer of Assistant Secretary rank or higher to serve as the Functional Coordinator for that function for the Federal Government.

3. Interagency Coordination: The Sector Liaison Officials and Functional Coordinators of the Lead Agencies, as well as representatives from other relevant departments and agencies, including the National Economic Council, will meet to coordinate the implementation of this directive under the auspices of a critical Infrastructure Coordination Group (CICG), chaired by the National Coordinator for security, Infrastructure Protection and counter-Terrorism. The National Coordinator will be appointed by me and report to me through the Assistant to the President for National Security Affairs, who shall assure appropriate coordination with the Assistant to the President for Economic Affairs. Agency representatives to the CICG should be at a senior policy level (Assistant secretary or higher). Where. appropriate, the CICG will be assisted by extant policy structures, such as the Security Policy Board, security Policy Forum and the National Security and Telecommunications and Information system security Committee.

4. National Infrastructure Assurance Council: On the recommendation of the Lead Agencies, the National Economic Council and the National Coordinator, I will appoint a panel of major infrastructure providers and state, and local government officials to serve as my National Infrastructure 
Assurance Council. I will appoint the Chairman. The National Coordinator will serve as the Council's Executive Director. The National Infrastructure Assurance Council will meet periodically to enhance the partnership of the public and private sectors in protecting our critical infrastructures and will provide reports to me as appropriate. Senior Federal Government officials will participate in the meetings of the National Infrastructure Assurance Council as appropriate.

\section{Protecting Federal Government Critical Infrastructures}

Every department and agency of the Federal Government shall be responsible for protecting its own critical infrastructure, especially its cyber-based systems. Every department and agency Chief Information officer (CIO) shall be responsible for information assurance. Every department and agency shall appoint a Chịef Infrastructure Assurance officer (CIAO) who shall be responsible for the protection of all of the other aspects of that department's critical infrastructure. The CIO may be double-hatted as the CIAO at the discretion of the individual department. These officials shall establish procedures for obtaining expedient and valid authorities to allow vulnerability assessments to be performed on government computer and physical systems. The Department of Justice shall establish legal guidelines for providing for such authorities.

No later than 180 days from issuance of this directive, every department and agency shall develop a plan for protecting its own critical infrastructure, including but not limited to its cyber-based systems. The National Coordinator shall be responsible for coordinating analyses required by the departments and agencies of inter-governmental dependencies and the mitigation of those dependencies. The Critical

Infrastructure Coordination Group (CICG) shall sponsor an expert review process for those plans. No later than two years from today, those plans shall have been implemented and shall be updated every two years. In meeting this schedule; the Federal Government shall present a model. to the private sector on how best to protect critical infrastructure. 
VIII. $\underline{\text { Tasks }}$

Within 180 days, the Principals Committee should submit to me a schedule for completion of a National Infrastructure Assurance Plan with milestones for accomplishing...the following subordinate and related tasks.

1. Vulnerability Analyses: For each sector of the: economy and each sector of the government that might be a target of infrastructure attack intended to significantly damage the United states, there shall be an initial vulnerability assessment, followed by periodic updates. As appropriate, these assessments shall also include the determination of the minimum essential infrastructure in each sector.

2. Remedial Plan: Based upon the vulnerability assessment, there shall be a recommended remedial plan. The plan shall identify timelines for implementation, responsibilities and funding.

3. Warning: A national center to warn of significant infrastructure attacks will be established immediately (see Annex A). As soon thereafter as possible, we will put in place an enhanced system for detecting and analyzing such attacks, with maximum possible participation of the private sector.

4. Response: We shall develop a system for responding to a significant infrastructure attack while it is underway, with the goal of isolating and minimizing damage.

5. Reconstitution: For varying levels of successful infrastructure attacks, we shall have a system to reconstitute minimum required capabilities rapidly.

6. Education and Awareness: There shall be Vulnerability Awareness and Education Programs within both the government and the private sector to sensitize people regarding the importance of security and to train them in security standards, particularly regarding cyber systems.

7. Research and Development: Federally-sponsored research and development in support of infrastructure protection shall be coordinated, be subject to multi-year planning, take into account private sector research, and be adequately funded to minimize our vulnerabilities on a rapid but achievable timetable. 
8. Intelligence: The Intelligence Community shall develop and implement a plan for enhancing collection and analysis of the foreign threat to our national infrastructure, to include but not be limited to the foreign cyber/information warfare threat.

9. International Cooperation: There shall be a plan to expand cooperation on critical infrastructure protection with likeminded and friendly nations, international, organizations and multinational corporations.

10. Legislative and Budgetary Requirements: There shall be an . evaluation of the executive branch's legislative authorities and budgetary priorities regarding critical infrastructure, and ameliorative recommendations shall be made to me as necessary. The evaluations and recommendations, if any, shall be coordinated with the Director of OMB.

The CICG shall also review and schedule. the taskings listed in Annex $B$.

IX. Implementation

In addition to the 180-day report, the National Coordinator, working with the National Economic Council, shall provide an annual report on the implementation of this directive to me and the heads of departments and agencies, through the Assistant to the President for National Security Affairs. The report should include an updated threat assessment, a status report on achieving the milestones identified for the National Plan and additional policy, legislative and budgetary recommendations. The evaluations and recommendations, if any, shall be coordinated with the Birector of OMB. In addition, following the establishment of an initial operating capability in the year 2000, the National Coordinator shall conduct a zero-based. review. 


\section{Annex A: Structure and Organization}

Lead Agencies: Clear accountability within the U.S. Government must be designated for specific sectors and functions. The following assignments of responsibility will apply.

Lead Agencies for Sector Liaison:

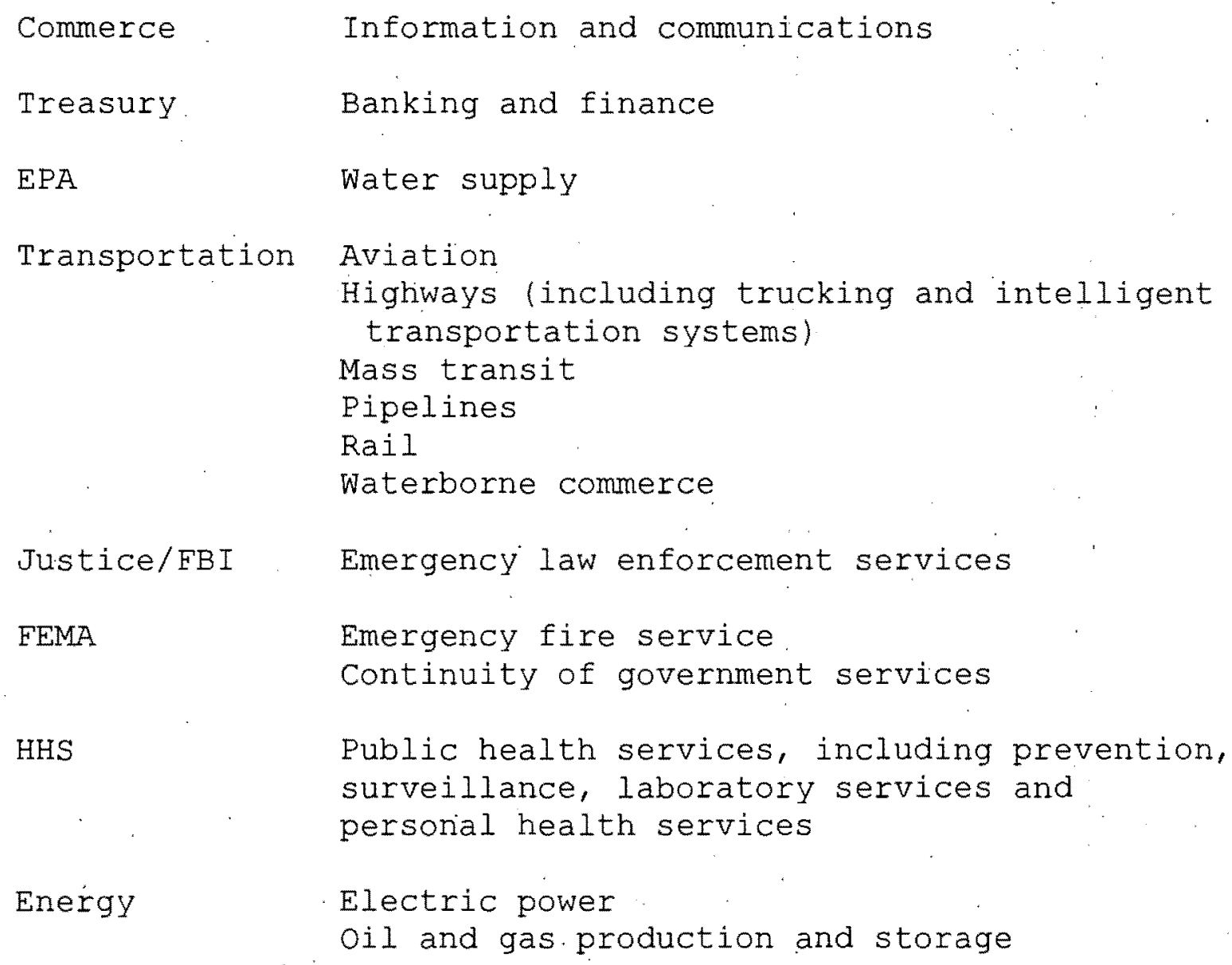

Lead Agencies for Special Functions: .

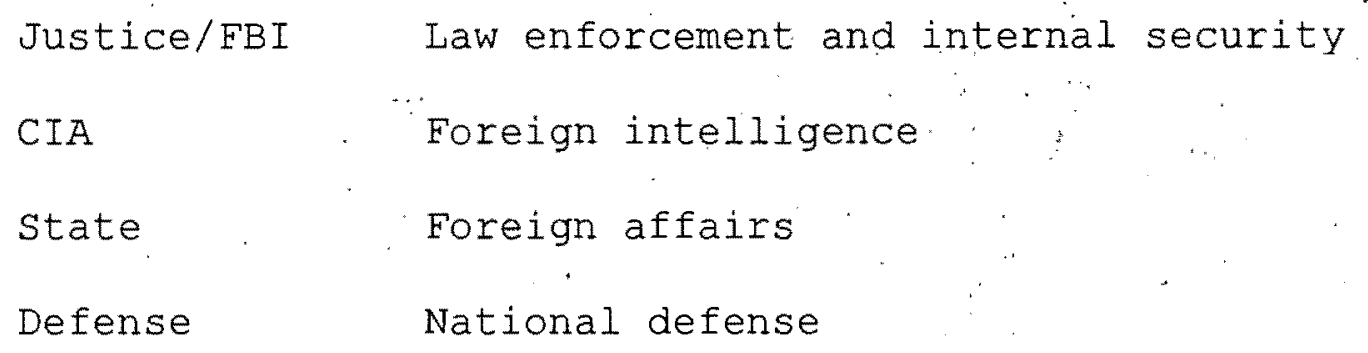

In addition, OSTP shall be responsible for coordinating research and development agendas and programs for the government through the National Science and Technology Council. Furthermore, while 
Commerce is the lead agency for information and communication, the Department of Defense will retain its Executive Agent responsibilities for the National Communications System and support of the President's National Security Telecommunications Advisory Committee.

National Coordinator: The National Coordinator for Security, Infrastructure Protection and Counter-Terrorism shall be. responsible for coordinating the implementation of this directive. The National Coordinator will report to me through the Assistant to the President for National Security Affairs. The National Coordinator will also participate as a full member of Deputies or Principals Committee meetings when they meet to consider infrastructure issues.. Although the National. Coordinator will not direct Departments and Agencies, he or she will ensure interagency coordination for policy development and implementation, and will review crisis activities concerning infrastructure events with significant foreign involvement. The National Coordinator will provide advice, in the context of the established annual budget process, regarding agency budgets for critical infrastructure protection. The National Coordinator will chair the Critical Infrastructure coordination. Group (CICG), reporting to the Deputies Committee (or, at the call of its chair, the Principals Committee). The sector Liaison Officials and Special Function Coordinators shall attend the CIGC's'meetings. Departments and agencies shall each appoint to the CIGC a senior official (Assistant secretary level or higher) who will regularly attend its meetings.: The National security Advisor shall appoint a Senior Director for Infrastructure Protection on the NSC staff.

A National Plan Coordination (NPC) staff will be contributed on a non-reimbursable basis by the departments and agencies, consistent with law. The NPC staff will integrate the various sector plans into a National Infrastructure Assurance Plan and. coordinate analyses of the U.S. Government's own dependencies on critical infrastructures. The NPC staff will also help coordinate a national education and awareness program, and legislative and public affairs.

The Defense Department shall continue to serve as Executive Agent for the Commission Transition office, which will form the basis of the NPC, during the remainder of FY98. Beginning in FY99, the NPC shall be an office of the Commerce Department. The office of Personnel Management shall provide the necessary assistance in facilitating the NPC's operations. The NPC will 
terminate at the end of FY01, unless extended by. Presidential directive.

\section{Warning and Information Centers}

As part of a national warning and information sharing system, I immediately authorize the FBI to expand its current organization to a full scale National Infrastructure Protection Center

(NIPC). This organization shall serve as a national critical infrastructure threat assessment, warning, vulnerability, and law enforcement investigation and response entity.. During the initial period of six to twelve months, I also direct the National Coordinator and the sector Liaison officials, working together with the Sector coordinators, the special. Function Coordinators and representatives from the National Economic Council, as appropriate, to consult with owners and operators of the critical infrastructures to encourage the creation of a private sector sharing and analysis center, as described below.

National Infrastructure Protection Center (NIPC): The NIPC will include FBI, USSS, and other investigators experienced in computer crimes and infrastructure protection, as well as representatives detailed from the Department of Defense, the Intelligence Community and Lead Agencies. It will be linked electronically to the rest of the Federal Government, including other warning and operations centers, as well as any private sector sharing and analysis centers. Its mission will include providing timely warnings of intentional threats, comprehensive analyses and law enforcement investigation and response.

All executive departments and agencies shall cooperate with the NIPC and provide such assistance, information and advice that the NIPC may request, to the extent permitted by law. All executive departments shall also share with the NIPC information about threats and warning of attacks and about actual attacks on critical government and private sector infrastructures, to the extent permitted by law. The NIPC will include elements responsible for warning, analysis, computer investigation, coordinating emergency response, training, outreach and development and application of technical tools. In addition, it will establish its own relations directly with others in the private sector and with any information sharing and analysis entity that the private sector may create, such as the Information Sharing and Analysis Center described below.

The NIPC, in conjunction with the information originating agency, will sanitize law enforcement and intelligence 
information for inclusion into analyses and reports that it will provide, in appropriate form, to relevant federal, state and local agencies; the relevant owners and operators of critical infrastructures; and to any private sector information sharing and analysis entity. Before disseminating national security or other information that originated from the inteligence community, the NIPC will coordinate fully with the intelligence. community through existing procedures. Whether as sanitized or unsanitized reports, the NIPC will issue attack warnings or alerts to increases in threat condition to any private sector information sharing and analysis entity and to the owners and operators. These warnings may also include guidance regarding additional protection measures to be taken by owners and : : operators. Except in extreme emergencies, the NIPC shall coordinate with the National Coordinator before issuing public warnings of imminent attacks by international terrorists, foreign states or other malevolent foreign powers.

The NIPC will provide a national focal point for gathering information on threats to the infrastructures. Additionally, the NIPC will provide the principal means of facilitating and coordinating the Federal Government's response to an incident, mitigating attacks, investigating threats and monitoring reconstitution efforts. Depending on the nature and level of a foreign threat/attack, protocols established between special function agencies (DOJ/DOD/CIA), and the ultimate decision of the President, the NIPC may be placed in a direct support role to either DOD or the Intelligence Community.

Information Sharing and Analysis Center (ISAC): The National Coordinator, working with Sector Coordinators, Sector Liaison Officials and the National Economic Council, shall consult with owners and operators of the critical infrastructures to strongly encourage the creation of a private sector information sharing and analysis center. The actual design and functions of the center and its relation to the NIPC will be determined by the private sector, in consultation with and with assistance from the Federal Government. Within 180 days of this directive, the National Coordinator, with the assistance of the CICG including the National Economic Council, shall identify possible methods of providing federal assistance to facilitate the startup of an ISAC.

Such a center could serve as the mechanism for gathering, analyzing, appropriately sanitizing and disseminating private sector information to both industry and the NIPC. The center could also gather, analyze and disseminate information from the 
NIPC for further distribution to the private sector. While: crucial to a successful government-industry partnership, this mechanism for sharing important information about vulnerabilities, threats, intrusions and anomalies is not to interfere, with direct information exchanges between companies. and the government.

As ultimately designed by private sector representatives, the ISAC may emulate particular aspects of such institutions as the Centers for Disease Control and Prevention that have proved. highly effective, particularly its extensive interchanges with the private and non-federal sectors. Under such a model; the ISAC would possess a large degree of technical focus and expertise and non-regulatory and non-law enforcement missions. It would establish baseline statistics and patterns on the various infrastructures, become a clearinghouse for information within and among the various sectors, and provide a library for historical data to be used be the private sector and, as deemed appropriate by the. ISAC, by the government. Critical to the success of such an institution would be its timeliness, accessibility, coordination, flexibility, utility and acceptability. 


\section{Annex B: Additional Taskings}

\section{Studies}

The National Coordinator shall commission studies on the following subjects:

- Liability issues arising from participation by private sector companies in the information sharing process.

- Existing legal impediments to information sharing, with an eye to proposals to remove these impediments, including through the drafting of model codes in cooperation with the American Legal Institute.

- The necessity of document and information classification and the impact of such classification on useful dissemination, as well as the methods and information systems by which threat and vulnerability information can be shared securely while avoiding disclosure or unacceptable risk of disclosure to those who will misuse it:

- The improved protection, including secure dissemination and information handling systems, of industry trade secrets and other confidential business data, law enforcement information and evidentiary material, classified national security information, unclassified material disclosing vulnerabilities of privately owned infrastructures and apparently innocuous information that, in the aggregate, it is unwise to disclose.

- The implications of sharing information with foreign entities where such sharing is deemed necessary to the security of United States infrastructures.

- The potential benefit to security standards of mandating, subsidizing, or otherwise assisting in the provision of insurance for selected critical infrastructure providers and requiring insurance tie-ins for foreign critical infrastructure providers hoping to do business with the United States. 


\section{Public Outreach}

In order to foster a climate of enhanced public sensitivity to the problem of infrastructure protection, the following actions shall be taken:

- The White House, under the oversight of the National Coordinator, together with the relevant Cabinet agencies shall consider a series of conferences: "(1) that will bring together national leaders in the public and private sectors to propose programs to increase the commitment to information security; (2) that convoke academic leaders from engineering, computer science, business and law schobls to review the status of education in information security and will identify changes in the curricula and resources necessary to meet the national demand for professionals in this field; (3) on the issues around computer ethics as these relate to the $K$ through 12 and general university populations.

- The National Academy of Sciences and the National Academy of Engineering shall consider a round table bringing together federal, state and local officials with industry and academic leaders to develop national strategies for enhancing infrastructure security.

- The intelligence community and law enforcement shall expand existing programs for briefing infrastructure owners and operators and senior government officials.

- The National Coordinator shall (1) establish a program for infrastructure assurance simulations involving senior public and private officials, the reports of which might be distributed as part of an awareness campaign; and (2) in coordination with the private sector, launch a continuing national awareness campaign, emphasizing improving infrastructure security.

\section{Internal Federal Government Actions}

In order for the Federal Government to improve its infrastructure security, these immediate steps shall be taken:

- The Department of Commerce, the General Services Administration, and the Department of Defense shall assist 
federal agencies in the implementation of best practices for information assurance within their individual.agencies.

- The National Coordinator shall coordinate a review of existing federal, state and local bodies charged with information assurance tasks, and provide recommendations on how these institutions can cooperate most effectively.

- All federal agenciés shall make clëar designations regarding who may authorize access to their computer systems.

- The Intelligence Community shall elevate and formalize the priority for enhanced collection and analysis of information on the foreign cyber/information warfare threat to our critical infrastructure.

- The Federal Bureau of Investigation, the Secret Service and other appropriate agencies shall: (1) vigorously recruit undergraduate and graduate students with the relevant computer-related technical skills for full-time employment as well as for part-time work with regional computer crime squads; and (2) facilitate the hiring and retention of qualified personnel for technical analysis and investigation involving cyber attacks.

- The Department of Transportation, in consultation with the Department of Defense, shall undertake a thorough evaluation of the vulnerability of the national transportation infrastructure that relies on the Global Positioning system. This evaluation shall include sponsoring an independent, integrated assessment of risks to civilian users of GPS-based systems, with a view to basing decisions on the ultimate architecture of the modernized NAS on these evaluations.

- The Federal Aviation Administration shall develop and implement a comprehensive National Airspace System Security Program to protect the modernized NAS from information-based and other disruptions and attacks.

- GSA shall identify large procurements (such as the new Federal Telecommunications system, FTS 2000) related to infrastructure assurance, study whether the procurement process reflects the importance of infrastructure protection and propose, if necessary, revisions to the overall procurement process to do so. 
- OMB shall direct federal agencies to include assigned infrastructure assurance functions within their Government Performance and Results Act: strategic planning and performance measurement framewörk.

- The NSA, in accordance' with its National Manager responsibilities in NSD-42, shall provide assessments encompassing examinations of U.S. Government systems to interception and exploitation; disseminate threat and vilnerability information; establish standards; conduct research and development; and conduct issue security product evaluations.

\section{Assisting the frivate Sector}

In order to assist the private sector in achieving and maintainjng infrastructure security:

- The National Coordinator and the National Infrastructure Assurance Council shall propose and develop ways to encourage private industry to perform periodic risk assessments of critical. processes, including information and telecommunications systems.

- The Department of Commerce and the Department of Defense shall work together, in coordination with the private sector, to offer their expertise to private owners and operators of critical infrastructure to develop security-related best practice standards.

- The Department of Justice and Department of the Treasury snall sponsor a comprehensive study compiling demographics of computer crime, comparing state approaches to computer crime and developing ways to deterring and responding to computer crime by juveniles.

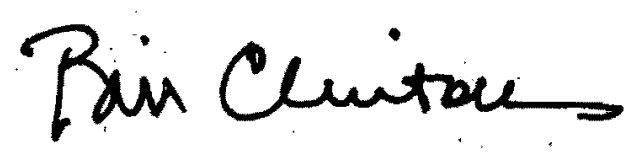

